\title{
Pequena inteligência estética
}

\author{
Luiz Armando Bagolin ${ }^{1}$
}

BENSE, Max. Inteligência brasileira: uma reflexão estética.

Tradução de Tercio Redondo, posfácio de Ana Luiza Nobre. São

Paulo: Cosac \& Naify, 2009, 120 p., 9 ils.

O pequeno livro de Max Bense intitulado Inteligência brasileira: uma reflexão cartesiana reúne-se à reedição, de agora, do já conhecido Pequena estética (Perspectiva, 1971), com o qual tentou, entre outras coisas, conhecer e interpretar a realidade nacional. Muitos dos textos presentes em Inteligência encontram-se diversamente escritos também na Pequena antologia bensiana, organizada por Haroldo de Campos, na parte final desta Pequena estética (Kleine Aesthetik, 1968). Postulante nas cifras da semiótica, das matemáticas e da filosofia hegeliana, ou de algum uso destas, a "estética informacional" bensiana aspira, após breves passagens do autor pelo Brasil, a uma visão espiritual julgada mais adequada, ainda não desencantada do mundo, especialmente do Novo Mundo, porquanto dialeticamente "metódica" e "criativa". Lançando mão de textos curtíssimos, cinquenta e três ao todo, de tom aforístico, Bense sobrevoa em Inteligência diversos assuntos, Brasília e o "projeto-piloto", Rio de Janeiro, o Aleijadinho, Guimarães Rosa, Clarice Lispector, Bruno Giorgi, elegendo-os como pretextos para alinhavar as suas teses sobre um Brasil progressista, na contramão da historicidade travadora, encontrada em lugares com processos de construção social, mais antigos. Trata-se de uma noção determinista, às avessas, em que pese ênfase do autor sobre o desenvolvimento de alguns "centros civilizados" de nossos trópicos.

Para Bense, estes não se entristecem, pois se conformam como os lugares onde se construíram aposentos racionalmente apropriados, como aquilo que foi desenhado a fim de conter o "que se desenrola dentro dele". O aposento, ou o seu projeto, simbolizado como o projeto-piloto, de Lúcio Costa e Oscar Niemeyer, coincide exatamente com o que contém, constituindo a sua tristeza somente "aquilo que lhe falta", caso, por ventura, lhe suceda faltar alguma coisa. Percebê-la, a falta, caso hou-

1 Professor da área de Artes do Instituto de Estudos Brasileiros (IEB/USP). E-mail: lbagolin@usp.br 
vesse, haja, parece nunca ter sido a intenção de Bense, ao descer em Brasília, acompanhado de João Cabral de Melo Neto, seu cicerone, pelo que a declara como "a primeira expressão visível de um cartesianismo na forma do design", algo feito na direção de uma obra de arte total, ou Gesamtkunstwerk, possível para o autor somente no Brasil.

Ao se formar de maneira "menos histórica", uma nação como a nossa, segundo Bense, tem seu modo de ser fundamentado mais no "gesto criador" do que no "contemplativo", sendo território propício, portanto, ao desenvolvimento de uma "inteligência cartesiana", entendida, pelo autor, como disposição à clareza na produtividade, assim como à indicação de seus métodos consecutivos. Coteja, sem notar grandes problemas quanto à possibilidade de abstrusão em seu discurso, o traçado de plano que corta o planalto do Distrito Federal, para demarcar e concretizar Brasília, com a comparação entre os modos de resolução de um problema aritmético em duas escolas, uma brasileira e outra alemã. Em ambos os casos, na construção de uma cidade no meio do cerrado, e na formulação de um problema matemático com vistas à instrução de crianças, a solução brasileira se mostraria mais inteligente, pois demonstraria, pela via prática, a explicitação dos meios de sua realização, mesmo em face daquilo que possa tornar a tarefa "absolutamente inviável". A natureza, opressiva nos trópicos, torna-se por si só um problema para a organização de algum método, segundo Bense, que possa auxiliar na construção de uma nova consciência voltada à vida coletiva na realização comunitária de uma ideia, "entrementes o páthos de uma preservada mistura de substâncias".

Em Brasília, levanta-se como resultado de um empreendimento delirante, junto à poeira avermelhada do solo, uma inteligência que se encanta com a aventura, principalmente, da realização da ideia. Delirando, Bense a pensa como exemplo contraposto ao de cidades como Rio, Belo Horizonte e Ouro Preto, pois se apagando nela o vir-a-ser, presente naquelas, o ser sendo tudo, perfaz-se a consciência coletiva como "autoconsciência refletida" na construção efetiva de um projeto que se pensa compreensivo de todas as classes, pela imantação, estética, da paisagem local. Prevalecendo na linguagem arquitetônica o conjunto e as grandes quadras, traçadas ortogonalmente, as habitações, escolas, bancos, jardins, ministérios, cupinzeiros e palácios cercados por autovias, misturam-se de forma logicamente organizada. Na verdade, Brasília fornecelhe o modelo exemplar para a construção do argumento sobre aquela suposta "inteligência", pois nela se reúne sem conflitos, segundo a sua crença, o "espírito tropical” e o "cartesiano". A fusão entre a organicidade e o vitalismo, inerentes ao primeiro, e a visada analítica pelo qual se 
instrumentaliza o segundo, é chave para Bense fundamentar a sua estética, não filosófica, baseada, sobretudo numa apropriação da semiótica peirceana, além da consulta explícita às teses de Christian von Ehrenfels. Contrastantes, mas não excludentes, os posicionamentos vistos no Brasil se orientam conforme "um caráter progressista”, não aferrado à história, ao moralismo e ao conservadorismo cristão, mas, antes, sucessivamente renovado graças a uma "essência em progresso".

Bense não viu, entretanto, na circulação de “todas as raças, pobres e ricos", conforme depõe em seu texto, a presença, ao lado dos cupins, de não poucos chupins, de toda a espécie, a morder o seu modelo de urbanidade cartesiana à brasileira. Insistente, faz circular em seu discurso a apologia à Brasília, evitando qualquer análise mais aprofundada sobre a situação, de grave aflição social, premente, já no início dos anos 60, quando a visitou três vezes, em suas zonas periféricas que, presume-se, nem sequer foram naquele consentidas. Às escusas de ter sido um grande incentivador das poéticas construtivas brasileiras, de noigandres e da "poesia concreta", por exemplo, pela qual se afirmaram os irmãos Campos, seus amigos, a sua crítica se produz de comentários que se tornaram por demais datados, restritos a determinados círculos intelectuais presentes, ou diluídos graças à massiva difusão atual, pelo agenciamento e marketing cultural. Consoante a determinadas posições das vanguardas, ou a alguns de seus discursos, a posição de Bense dá por manifesto a mudança de perspectiva das condições histórico-sociais a partir da intervenção racional e funcionalista representada por Brasília, e não de sua assimilação segundo modos e padrões de sociabilidade, assim como das condições econômicas daqueles que se estabeleceram no planalto central, desde a construção e a fundação daquela cidade.

Por exemplo, na comparação acima referida, o Rio de Janeiro, tratado como "cidade vegetativa", cidade de "pedestres", é apresentado por Bense como algo completamente oposto a Brasília, uma cidade "estrutural", linear e tecnológica. Ao "encarnar o princípio da pureza”, ou o “páthos da razão pura”, Brasília, segundo o autor, é antídoto ao provincianismo, sendo senda para um novo modelo de humanismo em que impera a necessidade da práxis comunicativa em detrimento da reflexão de cunho individual e existencial. Contrasta-a ainda com o que considera resquícios da "colonização cristã” representados pelas esculturas em pedra sabão de Congonhas do Campo, atribuídas ao Aleijadinho. Diferentemente, "o estilo colonial" interessa-lhe em Ouro Preto, pois o vê forjado por geometria que despoja a forma, na direção do que ajuíza ser o método cartesiano. Não o julga por si mesmo, obviamente, porque o valoriza apenas como modelo prévio, ou uma "clara antecipação do universo ide- 
acional matemático-construtivo do estilo concretista", como propõe, encarecendo novamente a aplicação do "método progressista". Ao elegê-lo, Bense o estende à literatura composta segundo os mesmos princípios, na "poesia concreta" em que experimentaram Augusto e Haroldo de Campos, Décio Pignatari, Ronaldo Azevedo, José Lino Grünewald e outros. Como a sua visão é positivada, a literatura que elogia se lhe apresenta conclusiva, quanto ao encerramento de um ciclo, o do "verso rítmicoformal", para o aparecimento de outro, representado pela produção dos concretos. Considera-a, portanto, inovadora quanto à desmobilização de uma poesia que tem no Ser e em sua essência o seu tema por excelência, para dar lugar a "uma comunicação materialmente estruturada", mais adequada aos tempos atuais, de circulação do signo. De caráter "acentuadamente supranacional”, porquanto pertencente à segunda fase do modernismo, de vocação internacionalista, a que pertence noigandres, a "poesia concreta" não está aberta a pressupostos, pois se resume, concretamente, a si mesma.

Bense força a mão em Hegel ao creditar-lhe a sua noção de "concreto" em oposição à de "abstração", pelo que pensa sobre o que é "em-si e para-si", ou o "espírito", conceito basilar para o filósofo do XIX, segundo o qual quanto mais próximo de si mesmo e conforme a sua natureza, mais o espírito dota a obra de arte da pura objetividade da ideia. Por isso é confusa a diretiva dada pelo autor quanto à arte concreta, como "arte material", dotando a palavra, principal recurso da linguagem, de "materialidade verbal, vocal e visual", tipificada pelo poema "vai e vem" de Grünewald, uma brincadeira, elevada à posição, pelo "construtivismo semiótico", de "signo-ser". Não se confunde este com o "ser do ente" que alguma literatura, decerto a romântica, reconhece num ente pré-dado. Não possui também, como enunciado, valor de verdade; antes tematiza o ser com a própria materialidade da poesia e dos recursos lexicais com os quais é construída. Escapa, portanto, por pouco, da monotonia, que o autor de antemão reconhece, aproximando-se da circularidade chatíssima que, na direção contrária à intuição, doente, para os defensores do metódico, ilumina o intelecto, de lampejo. Como em "a rose is a rose is a rose is a rose", de Gertrude Stein, além de outros poemas, de outros, "concretos" ou de associados àquele grupo. Usa, sem pudor, uma estrofe do poema de um desses, o conterrâneo Gottfried Benn, para justificar uma sesta após o almoço na casa de Carmen Portinho, no Rio, julgando-o, o sono, uma "paralisação efêmera da atualidade, não da potencialidade". No entanto, os esteios que ligam as suas reflexões sobre a poesia concreta e a arquitetura modernista, agora a de Affonso Reidy, arquiteto-autor da casa de Carmen, são frágeis, fazendo coincidir forçosamente os conceitos de 
estrutura em ambas, onde se estende certamente a rede para o seu merecido descanso que, a exemplo de suas viagens brasileiras, correu pelas expensas do Ministério de Relações Exteriores, do Brasil.

Bense não admite, parafraseando a referida estrofe do poema de Benn, que seu cérebro se converta "em prado, terra plana e pastores" e que os cupins e "viúvas-negras" lhe aterrem, ou aferrem o pensamento, apressando-se em decretar o declínio da vida do espírito no continente europeu, relativamente à nossa. Por isso, contesta o argumento de um viajante do século XVIII que passou por aqui, denominando o lugar de "exótico", em virtude do grau de amoralidade, conforme a sua impressão, que beirava a floresta tropical. Confronta-lhe a "inteligência brasileira" perante a qual se dá a "relatividade dos julgamentos morais" à medida que se explicitam os "seus traços criativos".

A revolução, caso venha, no caso brasileiro, se dará em virtude deste "amoralismo", sugere Bense, a fim de "não assumir um caráter missionário". Em vista da ameaça à condição de liberdade, "vez ou outra", no Brasil, adverte o autor, esta "não pode servir ao poder como método de opressão", seja pela direita, seja pela esquerda. Mas, sem optar por um dos dois lados, o do poder ou o de sua oposição, Bense desvia-se de ambos na prosa, optando por apontar a liberdade "como um estado de consciência", como "liberdade criativa" derivada do método fundado nos princípios “da dúvida” e "da demonstração". Demonstra que não deseja aprofundar-se sobre as questões, conflitivas, no campo social e político, que dividem a sociedade brasileira, para que não the esmoreça o modelo, estereotipado, de "inteligência cartesiana", que quer fazer acreditar ter se tornado possível por estas plagas.

Anteriormente, Bense dedica muitas páginas à escultura de Bruno Giorgi, como exemplo daquilo que define como "quase-geometria" ou "representação dinâmica do prospectivo". Nela subsistem, à luz de algum vestígio do pensamento hegeliano, pouco provável, o "geométrico" e o "orgânico", como sucedâneos do "estrutural" e do "vegetativo", ou do "topológico" e do "morfológico", oscilando entre a figuração e a nãofiguração na direção da feitura de figuras-troncos. Da "ramagem” de Desargues, geômetra do século XVII, Bense retira o conceito de nodais que estende às estruturas de Giorgi, notadamente quanto à percepção de suas sombras, conquanto estas não apresentem possivelmente desabonadoras, quanto ao pretendido caráter progressista, as tradicionais bases e plintos de suas esculturas. Lida no Brasil de hoje, o tom apologético em relação à arte de Bruno Giorgi, predominante nestas páginas, surpreende, sobretudo porque, na posição de artista merecedor das encomendas oficiais, no momento de Brasília, e um pouco depois, não deixou o mesmo 
de ser o alvo da indiferença e da desaprovação do grupo dos concretos que Bense, igualmente, elogia.

A remissão à prosa de Guimarães Rosa, ao contrário, encontra, em relação aos concretos, apoio óbvio. O fato de ter sido objeto de um longo ensaio feito por Augusto de Campos, comparando-o ao Joyce de Finnegans Wake, além de admirado por Haroldo, faz com que Bense o acolha às suas preferências literárias, também pelo alto grau de experimentalismo feito com a língua no decurso do romance. Trata-o, o livro Grande sertão: veredas, na chave de “teodicéias monadológicas”, seja lá o que for isso, sublinhando o gosto de Rosa pela "mistura, pelas entropias extremas, pelos estados ergódicos”. Alça-o à posição da poética experimental que advoga, devido aos jogos sintáticos que o escritor utiliza, em "momentos joyceanos", de re-montagem da língua, a par dos limites linguísticos, não disfarçando o "risinho" daquele, na intimidade de uma conversa com Bense, semelhante ao de uma velha, a formulação lexical complexa de sua obra, que se desenvolve a partir da parole portemante$a u$, a "palavra-valise", conforme Haroldo de Campos.

Bem melhor, no entanto, aquele riso desajeitado e tímido, de Rosa, certamente, do que o riso mascado que nos toma quando apresentados àqueles joguinhos de composição e decomposição de significantes, tal como o "luxo-lixo-luxo", de outrora. Sua justeza e logicidade não resistiram à produção crítica mesmo de personalidades supérstites, concretas ou neoconcretas, que viveram a efervescente discussão semiológica daqueles tempos. Como bem ilustra, atualmente, o louvor ao lixo transformado em luxo, em museus de arte moderna, como arte? de Viks da vida. 